\title{
Impacts of Comorbidities on the Association between Arterial Stiffness and Obstructive Sleep Apnea in the Elderly
}

\author{
Tae Kim $^{a}$ Chung Suk Lee ${ }^{a}$ Sang Don Lee ${ }^{b}$ Suk-Hoon Kang ${ }^{c}$ Ji Won Han ${ }^{a}$ \\ Atul Malhotra ${ }^{\mathrm{e}}$ Ki Woong Kim ${ }^{\text {a,d }}$ In-Young Yoon ${ }^{\text {a,d }}$ \\ ${ }^{a}$ Department of Neuropsychiatry, Seoul National University Bundang Hospital and ${ }^{b}$ Department of Psychiatry, \\ Korean Armed Forces Capital Hospital, Gyeonggi-do, 'Department of Psychiatry, Seoul Veterans Hospital and

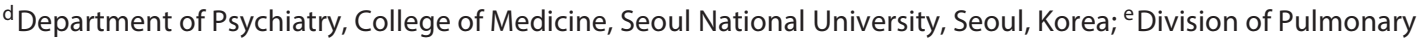 \\ and Critical Care Medicine, School of Medicine, University of California, San Diego, Calif., USA
}

\section{Key Words}

Obstructive sleep apnea - Arterial stiffness .

Elderly population $\cdot$ Pulse wave velocity $\cdot$ Lung

\begin{abstract}
Background: Although the impact of obstructive sleep apnea (OSA) on cardiovascular risk is reasonably well established in middle-aged patients, the debate persists as to whether OSA also increases this risk in the elderly. Arterial stiffness has been used as an early independent predictor of cardiovascular risk. Study Objectives: We sought to determine whether OSA has significant effects on the arterial stiffness in the elderly population and evaluate the impact of comorbidities on the association between arterial stiffness and OSA. Methods: We performed a cross-sectional study in a university hospital. Elderly participants ( $\geq 60$ years) were invited to participate in our study between November 2010 and January 2013. OSA was diagnosed using gold standard polysomnography and arterial stiffness was assessed by brachial-ankle pulse wave velocity (baPWV), cardio-ankle vascular index (CAVI) and central systolic and diastolic blood pressure (CSBP and CDBP). The high-sensitivity C-reactive protein (hs-CRP) level was also measured. Results: We found no significant association between the severity of OSA and the ar-
\end{abstract}

terial stiffness-related parameters CSBP, CDBP, baPWV, CAVI and hs-CRP. However, in patients with no comorbid medical conditions or use of medications ( $n=101)$, we showed a modest association between OSA and arterial stiffness-related parameters and hs-CRP. Conclusion: We conclude that OSA is associated with increased arterial stiffness in an otherwise healthy elderly population, although the association was obviated by comorbidities and medications perhaps due to ceiling effects.

(c) 2015 S. Karger AG, Basel

\section{Introduction}

Obstructive sleep apnea (OSA) is characterized by repetitive pauses in breathing during sleep resulting in an intermittent reduction in blood oxygen saturation. The prevalence of OSA is about $6-13 \%$ in the middle-aged population with higher values of up to $19-37 \%$ in older individuals [1-3]. In the era of population aging, OSA in older people might be a serious health threat, but the consequences of OSA in the elderly have been debated. OSA is known to increase the risk of mortality and cardiovascular diseases such as coronary artery disease, heart failure and stroke [4-7]. In older people, some authors have

\section{KARGER 125}

(c) 2015 S. Karger AG, Base

0025-7931/15/0894-0304\$39.50/0

E-Mail karger@karger.com

www.karger.com/res
In-Young Yoon, $\mathrm{MD}, \mathrm{PhD}$

Department of Neuropsychiatry

Seoul National University Bundang Hospital

Gumi-dong, Seongnam-si, Gyeonggi-do, 463-707 (Korea)

E-Mail iyoon@snu.ac.kr 
shown that OSA is also associated with increased blood pressure (BP) [8], high cardiovascular risk $[4,5]$ and high mortality [9]. On the other hand, others have shown that OSA in the elderly is not associated with either systolic/ diastolic hypertension or mortality $[10,11]$.

Arterial stiffness has been implicated as an early independent predictor of cardiovascular risk in OSA patients $[12,13]$. There are several indices for measuring arterial stiffness such as brachial-ankle pulse wave velocity (baPWV) and the cardio-ankle vascular index (CAVI). A substantial body of evidence shows that these measurements of arterial stiffness are increased in middle-aged patients with OSA [12], and our group has also shown an association of nocturnal hypoxemia and arterial stiffness in middle-aged male OSA patients [14]. However, there is a paucity of research addressing the association between arterial stiffness, an early marker of cardiovascular risk, and OSA in the elderly population. Considering the controversies regarding OSA in the elderly, we sought to test the hypothesis that elderly OSA patients would have greater vascular stiffness than matched individuals without OSA, independent of known comorbidities. Since the elderly frequently present with comorbid medical conditions, excluding those with comorbidities might only result in an artificially healthy group of the elderly. Conversely, the impact of comorbidities on vascular stiffness might lead to ceiling effects which would limit the ability to assess the impact of OSA. Moreover, certain comorbidities such as hypertension and diabetes may be causally linked to OSA, which further complicates the decision of whether to include or exclude these patients in rigorous analyses. Thus, we planned to assess elderly OSA patients with and without known comorbidities to allow determination of the impact of OSA on vascular stiffness and potential interactive effects with comorbidities.

\section{Methods}

\section{Study Subjects}

We conducted a cross-sectional observational study of 471 elderly individuals, at least 60 years of age, who were recruited by convenience sampling from the sleep laboratory of the Seoul National University Bundang Hospital, Seongnam-si (and adjacent communities), South Korea, by advertisement between November 2010 and January 2013. We excluded patients with a history of prior therapy for snoring or OSA, heart failure, cerebrovascular diseases with neurologic deficits, inflammatory diseases, chronic obstructive pulmonary disease, nocturnal asthma, Cheyne-Stoke respiration and other sleep disorders such as parasomnias and circadian rhythm disorders. All of the participants underwent nocturnal polysomnography and clinical evaluation. Our Institution- al Review Board approved the study (B-1006/103-010), and a signed informed consent was obtained from all of the subjects or from their legal guardians.

\section{Clinical Evaluation}

Clinical data were collected using a standardized protocol, including questions about current medical conditions and medication use, the Pittsburgh Sleep Quality Index and the Epworth Sleepiness Scale (ESS). Hypertension was defined as systolic BP $\geq 140 \mathrm{~mm} \mathrm{Hg}$, diastolic BP $\geq 90 \mathrm{~mm} \mathrm{Hg}$ or the current use of antihypertensive medications. Diabetes mellitus was defined as a fasting blood glucose level $\geq 126 \mathrm{mg} / \mathrm{dl}$ or current use of antidiabetic medications. Metabolic dyslipidemia was considered to be present if subjects were taking lipid-lowering medications at recruitment or had a high level of serum triglyceride $(\geq 150 \mathrm{mg} / \mathrm{dl})$ or a low level of high-density lipoprotein cholesterol $(\leq 50 \mathrm{mg} / \mathrm{dl}$ for men and $\leq 40 \mathrm{mg} / \mathrm{dl}$ for women) $[15,16]$. Laboratory tests were carried out for measuring the lipid profile and levels of high-sensitivity Creactive protein (hs-CRP), fasting blood sugar and insulin.

\section{Nocturnal Polysomnography}

We used the Embla N7000 (Embla, Reykjavik, Iceland) with standard electrodes and sensors. Electroencephalography electrodes were applied at C4/A1, C3/A2, O1/A2 and O2/A1, and two electrooculography electrodes were applied on the sides of both eyes to record horizontal and vertical eye movements. Electromyography electrodes were applied on the submentalis muscles and both anterior tibialis muscles. Strain gauges were used for recording chest and abdominal respiratory movements, and nasal pressure cannulae were used to record airflow. Oxygen saturation was measured using a pulse oximeter applied on the index finger. Based on the criteria of Rechtschaffen and Kales [17], sleep was scored at every 30 -second epoch of the nocturnal polysomnography. Apnea was defined as complete cessation of airflow for at least $10 \mathrm{~s}$. Hypopnea was defined as a discernible reduction in airflow for at least $10 \mathrm{~s}$ associated with electroencephalographic arousal or oxygen desaturation $(\geq 4 \%)$ [18]. The apnea-hypopnea index (AHI) was defined as the total number of apneas and hypopneas per hour of sleep, and the oxygen desaturation index (ODI) was calculated as the number of oxygen desaturations $(\geq 4 \%)$ per hour of sleep. OSA was diagnosed if AHI was $\geq 15 / \mathrm{h}$, and was divided into 2 groups, i.e. mild-to-moderate OSA (AHI between 15 and $29 / \mathrm{h})$ and severe $(\mathrm{AHI} \geq 30 / \mathrm{h})$ OSA [9].

\section{Assessment of Arterial Stiffness}

Arterial stiffness was assessed by brachial-ankle pulse wave velocity (baPWV), cardio-ankle vascular index (CAVI) and central $\mathrm{BP}$, both systolic (cSBP) and diastolic (cDBP). To evaluate baPWV, we measured electrocardiogram, phonocardiogram and oscillometric signals from 4 extremities and the ankles as well as tonometric signals from the right common carotid and right femoral arteries with a noninvasive vascular screening device system (VP-2000; Omron-Colin, Kyoto, Japan) [19]. The measurement of baPWV and CAVI was performed based on the literature $[13,20]$. The time interval between the wave front of the brachial waveform and that of the ankle waveform was defined as the time interval between the brachium and ankle ( $\Delta \mathrm{Tba})$. The path length from the suprasternal notch to the brachium (Lb) and ankle (La) was obtained from superficial measurements and was calculated using the following equations: $\mathrm{Lb}=0.2195 \times$ height $($ in $\mathrm{cm})-2.0734 ; \mathrm{La}=$ 
Table 1. Clinical characteristics of the study population

\begin{tabular}{|c|c|c|c|c|}
\hline Variable & $\begin{array}{l}\text { Normal } \\
(\text { AHI <15/h) }\end{array}$ & $\begin{array}{l}\text { Mild-to-moderate } \\
(15 \leq \mathrm{AHI}<30 / \mathrm{h})\end{array}$ & $\begin{array}{l}\text { Severe } \\
(\mathrm{AHI} \geq 30 / \mathrm{h})\end{array}$ & $\mathrm{p}$ value \\
\hline Total number of subjects & 226 & 127 & 118 & \\
\hline Age, years & $67.9 \pm 5.60$ & $67.7 \pm 5.43$ & $68.2 \pm 5.73$ & 0.743 \\
\hline BMI, $\mathrm{kg} / \mathrm{m}^{2}$ & $23.3 \pm 2.47^{\mathrm{a}}$ & $24.4 \pm 2.79^{\mathrm{a}}$ & $25.5 \pm 3.17^{\mathrm{a}}$ & $<0.001^{*}$ \\
\hline Current smokers & $12(5.4)$ & $12(9.5)$ & $13(12.4)$ & 0.078 \\
\hline Diabetes & $44(19.5)$ & $24(18.9)$ & $26(22.0)$ & 0.802 \\
\hline Dyslipidemia & $98(43.6)$ & $53(42.1)$ & $52(44.4)$ & 0.930 \\
\hline
\end{tabular}

Data are presented as $\mathrm{n}(\%)$ or means $\pm \mathrm{SD} .{ }^{\dagger} \mathrm{p}<0.05, \chi^{2}$ test; ${ }^{*} \mathrm{p}<0.05$, ANOVA.

a A pairwise comparison was made between the means for each AHI subgroup with Bonferroni's correction $(\mathrm{p}<0.05)$.

$0.8129 \times$ height $($ in $\mathrm{cm})+12.328$. Finally, baPWV was calculated by the following equation: baPWV $=(\mathrm{La}-\mathrm{Lb}) / \Delta \mathrm{Tba}[20]$. We measured baPWV after at least 5 min of rest, and then CAVI was calculated using the following equation: $\mathrm{CAVI}=2 \rho \times 1 /(\mathrm{Ps}-\mathrm{Pd}) \times$ $\ln (\mathrm{Ps} / \mathrm{Pd}) \times \mathrm{baPWV}^{2}$, where $\rho$ is the density of blood and Ps and $\mathrm{Pd}$ are the SBP and DBP, respectively [13]. cBPs were assessed noninvasively using an algorithm that derives the pressure wave at the ascending aorta from an external measurement taken at the radial artery (SphygmoCor; AtCor Medical, Itasca, Ill., USA).

\section{Statistical Analysis}

Subjects were divided into 3 subgroups based on the AHI, i.e. normal (AHI $<15 / \mathrm{h})$, mild-to-moderate $(15 \leq \mathrm{AHI}<30 / \mathrm{h})$, and severe OSA (AHI $\geq 30 / \mathrm{h})$. We used an AHI cut-off value of 15 for making the diagnosis of OSA (control group) in the elderly [1]. Comparison between subgroups was done with analysis of covariance after adjusting for body mass index (BMI) and gender. Multiple linear regression analysis was used to determine the relationship between cardiovascular variables as dependent variables and polysomnographic and clinical variables as independent variables. All significance tests were 2 -sided and $\mathrm{p}<0.05$ was considered statistically significant. Statistical analysis was done with SPSS version 18.0 for Windows (SPSS Inc., Chicago, Ill., USA).

\section{Results}

\section{Clinical Characteristics of Subjects}

Overall, $71.0 \%$ of male and $34.7 \%$ of female subjects were diagnosed as having OSA. Table 1 shows the clinical characteristics of the study population. Age did not differ across the 3 subgroups, i.e. normal $(n=226,68.0 \pm 5.6$ years), mild-to-moderate OSA ( $\mathrm{n}=127,67.7 \pm 5.4$ years) and severe OSA ( $\mathrm{n}=118,68.2 \pm 5.7$ years). We found that the proportion of male subjects and BMI were different among subgroups $\left(\chi^{2}=67.34\right.$, d.f. $=2, \mathrm{p}<0.001$ and $\mathrm{F}=$ 26.21, d.f. $=2, \mathrm{p}<0.001$, respectively). Hypertension, di- abetes and dyslipidemia were equally distributed among the AHI subgroups $(\mathrm{p}=0.498, \mathrm{p}=0.802$ and $\mathrm{p}=0.930$, respectively). The proportion of medicated subjects with hypertension, diabetes and dyslipidemia in the comorbidity group was $80.4,70.8$ and $43.3 \%$, respectively.

\section{Polysomnographic Findings and Arterial}

Stiffness-Related Variables

We compared scales for sleep quality and sleepiness, polysomnographic findings and arterial stiffness-related variables among the 3 groups defined by AHI (table 2). As expected, subjective sleepiness measured by ESS was higher in the severe OSA group ( $\mathrm{p}=0.001$ by ANOVA; $\mathrm{p}=0.001$ between the normal and severe OSA group by post hoc test with Bonferroni's method). Polysomnographic data showed significant group differences in AHI, the lowest oxygen concentration (\% of sleep time), oxygen desaturation $<90 \%$ ( $\%$ of sleep time) and ODI ( $\mathrm{p}<$ $0.001, \mathrm{p}<0.001, \mathrm{p}<0.001$ and $\mathrm{p}<0.001$, respectively). However, we could not identify any significant difference in cardiovascular variables such as cSBP, cDBP, baPWV, CAVI and hs-CRP $(\mathrm{p}=0.118, \mathrm{p}=0.159, \mathrm{p}=0.202, \mathrm{p}=$ 0.062 and $\mathrm{p}=0.154$, respectively).

\section{Subgroup Analysis: Comorbidity and Healthy Groups}

We stratified the subjects into 2 groups for subgroup analysis by design, i.e. the comorbidity group $(n=370)$ and the group with no comorbidities, i.e. the healthy group $(\mathrm{n}=$ 101). The AHI subgroups in the healthy group did not differ in the proportion of males and BMI but those in the comorbidity group $\operatorname{did}\left(\chi^{2}=68.1\right.$, d.f. $=2, p<0.001$ and $\mathrm{F}=25.3$, d.f. $=2, \mathrm{p}<0.001$, respectively). Therefore, adjustment for gender and BMI was performed only for the comorbidity group. The healthy group revealed a significant 
Table 2. Polysomnographic and cardiovascular variables of all subjects

\begin{tabular}{lcccc}
\hline & \multicolumn{2}{c}{ All subjects $(\mathrm{n}=471)$} & & p value \\
\cline { 2 - 4 } & normal $(\mathrm{n}=226)$ & mild-to-moderate $(\mathrm{n}=127)$ & severe $(\mathrm{n}=118)$ \\
\hline PSQI & $6.49(0.27)$ & $7.18(0.34)$ & $7.55(0.39)$ & 0.077 \\
ESS & $6.71(0.32)^{\mathrm{a}}$ & $7.31(0.40)$ & $8.16(0.46)^{\mathrm{a}}$ & $0.048^{*}$ \\
AHI, events/h & $6.79(0.51)^{\mathrm{a}}$ & $21.62(0.65)^{\mathrm{a}}$ & $46.56(0.71)^{\mathrm{a}}$ & $<0.001^{*}$ \\
Lowest $\mathrm{O}_{2}^{\mathrm{b}}, \%$ & $87.78(0.39)^{\mathrm{a}}$ & $84.24(0.49)^{\mathrm{a}}$ & $78.59(0.53)^{\mathrm{a}}$ & $<0.001^{*}$ \\
Desat. $<90 \%{ }^{\mathrm{c}}, \%$ & $1.20(0.52)^{\mathrm{a}}$ & $1.58(0.66)$ & $8.83(0.72)^{\mathrm{a}}$ & $<0.001^{*}$ \\
ODI & $5.02(0.66)^{\mathrm{a}}$ & $14.83(0.84)^{\mathrm{a}}$ & $36.01(0.91)^{\mathrm{a}}$ & $<0.001^{*}$ \\
cSBP, mm Hg & $115.4(1.05)$ & $118.6(1.32)$ & $118.5(1.44)$ & 0.118 \\
cDBP, mm Hg & $74.6(0.63)$ & $75.9(0.80)$ & $1,675.3(282.7)$ & 0.159 \\
baPWV, cm/s & $1,632.9(19.6)$ & $1,633.9(248.0)$ & $6.25(0.20)$ & 0.202 \\
CAVI & $5.64(0.14)$ & $5.79(0.18)$ & $1.39(0.15)$ & 0.062 \\
hs-CRP, mg/l & $1.04(0.11)$ & $1.31(0.14)$ & 0.154 \\
\hline
\end{tabular}

Data are presented as means $(\mathrm{SEM})$. PSQI $=$ Pittsburgh Sleep Quality Index. ${ }^{*} \mathrm{p}<0.05$, gender- and BMI-adjusted ANCOVA.

a A pairwise comparison was made between the means of the subgroups with Bonferroni's correction $(\mathrm{p}<0.05)$.

${ }^{b}$ Lowest $\mathrm{O}_{2}$ saturation during sleep study.

${ }^{c}$ Percentage of sleep with a desaturation of $\mathrm{O}_{2}<90 \%$.

Table 3. Polysomnographic and cardiovascular variables of subjects in the comorbidity and healthy group

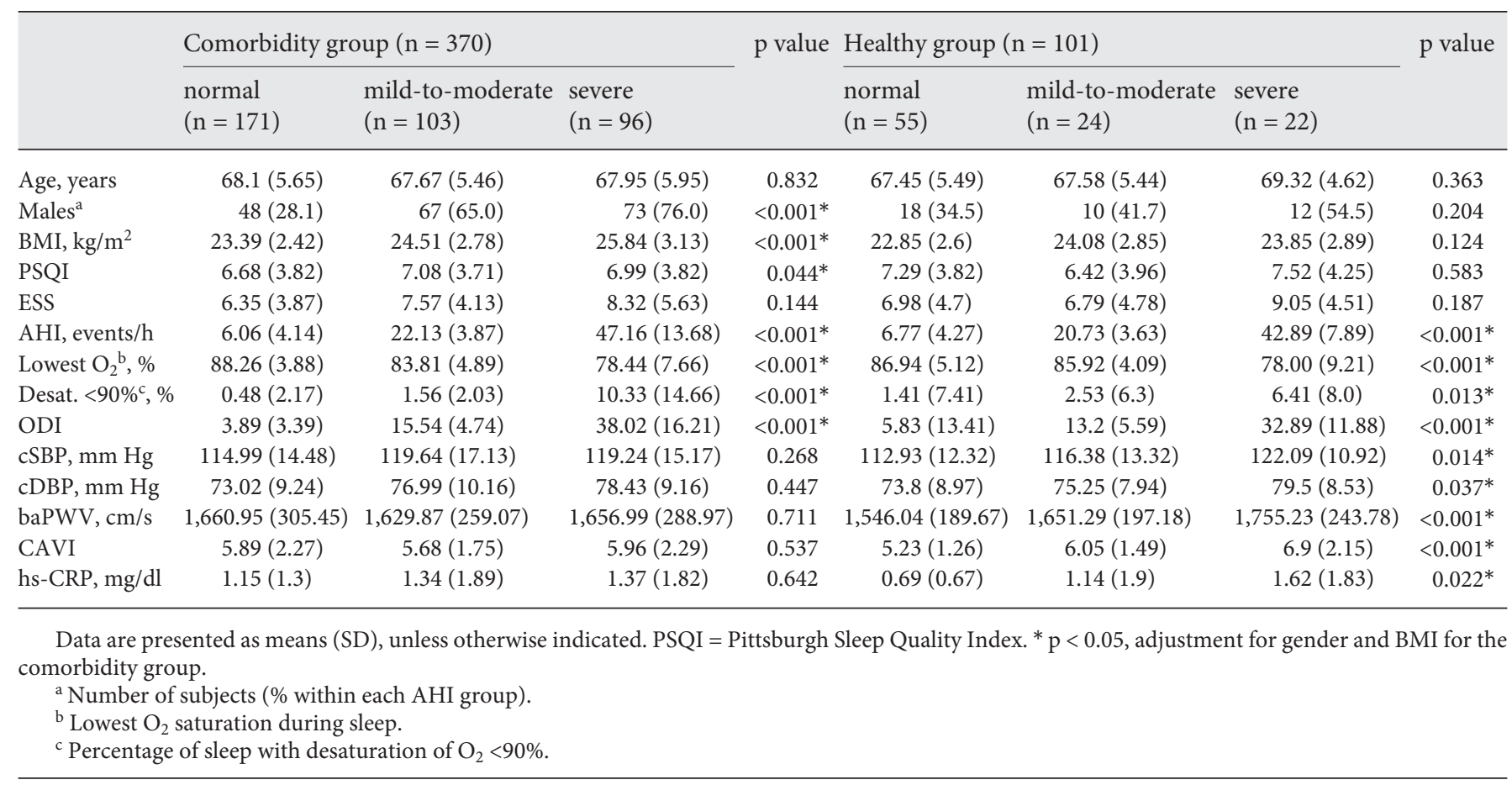

subgroup difference in cSBP, cDBP, baPWV, CAVI and hs-CRP $(\mathrm{F}=4.460, \mathrm{p}=0.014 ; \mathrm{F}=3.408, \mathrm{p}=0.037 ; \mathrm{F}=8.703$, $\mathrm{p}<0.001 ; \mathrm{F}=9.554, \mathrm{p}<0.001 ; \mathrm{F}=3.953, \mathrm{p}=0.022$, respectively; table 3 ; fig. 1). In figure $1, \mathrm{cSBP}$ represents all cBPs because the results for $\mathrm{CDBP}$ were similar. In contrast, the comorbidity group did not show subgroup differences in any of cSBP, cDBP, baPWV, CAVI or hs-CRP ( $\mathrm{F}=1.320$, $\mathrm{p}=0.268 ; \mathrm{F}=0.808, \mathrm{p}=0.447 ; \mathrm{F}=0.341, \mathrm{p}=0.711 ; \mathrm{F}=$ $0.623, \mathrm{p}=0.537 ; \mathrm{F}=0.443, \mathrm{p}=0.642$, respectively). Within the comorbidity group, further subgroup analysis for the 


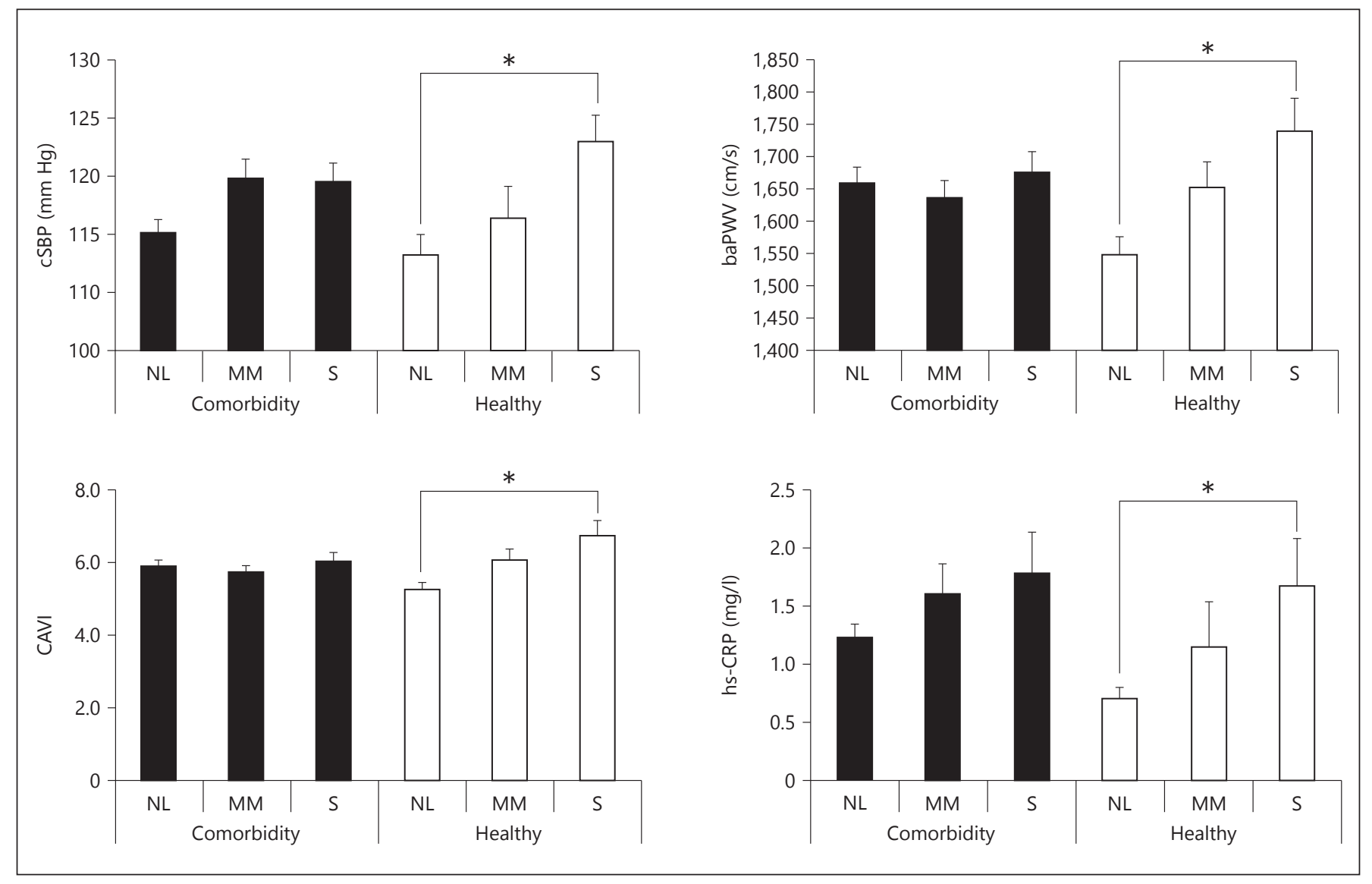

Fig. 1. The normal AHI and severe OSA subgroups of the healthy group showed differences in cSBP, baPWV, CAVI and hs-CRP. Black and white bars indicate the mean of the comorbidity and healthy groups, respectively, and the error bars show the SEM.
$* \mathrm{p}<0.05$, post hoc test by Bonferroni's method following ANOVA. $\mathrm{NL}=$ Normal group; $\mathrm{MM}=$ mild-to-moderate OSA group; $\mathrm{S}=$ severe OSA group.

\section{Discussion}

We studied the elderly population for assessing the relationship between OSA and arterial stiffness. The elderly patients with OSA did not show an association between AHI and arterial stiffness-related variables, but the subgroup without comorbidities revealed a modest association between $\mathrm{AHI}$ and the given variables, cSBP, cDBP, baPWV and CAVI and the systemic inflammatory marker hs-CRP.

Arterial stiffness is one of the important biological markers for arterial health at various sites in the arterial system and is caused by structural changes in the vascular wall including fibrosis, medial smooth-muscle cell necrosis, breaks in elastin fibers, calcification and diffusion of macromolecules into the arterial wall [21]. Greater arterial stiffness is associated with atherosclerosis [22], which increases the risk of cardiovascular diseases and events. PWV is the most thoroughly and clinically investigated 
Table 4. Multiple linear regression analysis of arterial stiffness variables in the healthy group

\begin{tabular}{lrrrrr}
\hline Independent variables & \multicolumn{2}{l}{ Dependent variables } & & \\
\cline { 2 - 6 } & cSBP & cDBP & baPWV & CAVI & hs-CRP \\
\hline AHI & $0.286(0.007)^{*}$ & $0.232(0.024)^{*}$ & $0.326(0.002)^{*}$ & $0.326(0.002)^{*}$ & $0.333(0.002)^{*}$ \\
Sex & $-0.103(0.478)$ & $-0.271(0.061)$ & $-0.119(0.415)$ & $-0.102(0.486)$ & $0.209(0.152)$ \\
BMI, kg/m ${ }^{2}$ & $0.113(0.271)$ & $0.080(0.428)$ & $-0.015(0.882)$ & $-0.029(0.782)$ & $0.045(0.657)$ \\
Current smoker & $-0.007(0.960)$ & $-0.010(0.945)$ & $-0.128(0.381)$ & $-0.154(0.293)$ & $0.092(0.523)$ \\
\hline
\end{tabular}

Data are presented as a standardized $\beta$ coefficient ( $\mathrm{p}$ value). ${ }^{*} \mathrm{p}<0.05$, multiple linear regression.

measure of arterial stiffness, defined as the wave speed within a material (distance travelled/transit time) [12]. The association between OSA and arterial stiffness has been studied by many researchers; a review conducted by Philips et al. [12] summarized that 20 out of 28 crosssectional studies on middle-aged patients found a significant difference in arterial stiffness between controls and patients with OSA. baPWV has been suggested as a predictor of the presence of coronary artery disease; however, in patients with OSA, it can be affected by changes in BP during measurement [22]. Thus, CAVI was an improved measurement obtained by adjusting peripheral BPs so that the effect of BP at the time of the measurement might be reduced [23]. Recently, good reproducibility of CAVI was validated in OSA [13]. It is also noteworthy that $\mathrm{CBPs}$ are closely related to arterial stiffness and are more relevant than peripheral $\mathrm{BP}$ in the pathogenesis of cardiovascular diseases [24].

After we demonstrated that nocturnal hypoxemia is associated with arterial stiffness and endothelial dysfunction in the middle-aged $[14,25]$, we questioned whether OSA in the elderly could also have an impact on arterial stiffness. Previous studies on the association between OSA and arterial stiffness were performed with middle-aged patients [12]. To the best of our knowledge, ours is the first cross-sectional study to investigate the association between OSA and arterial stiffness exclusively in an elderly population. Unlike the middle-aged population, the elderly with OSA did not show an association between OSA and arterial stiffness-related variables. Evaluation of endothelial dysfunction could yield positive results [26], but has been reported that in older adults, the measurements for both arterial stiffness and endothelial dysfunction are directly associated, thus providing similar information $[27,28]$. On the other hand, as the elderly are prone to various diseases and consequently take more medications, we analyzed a subgroup without comorbidities. A relationship between OSA and arterial stiffness was found in this healthy group. Our subgroup analysis based on medication status within the comorbidity group showed no worsening of arterial stiffness according to OSA in both the medication and nonmedication subgroups. For the nonmedication subgroup, medical conditions per se, like hypertension, diabetes and dyslipidemia, might aggravate arterial stiffness regardless of the presence of OSA $[29,30]$ whereas for the medication subgroup, antihypertensive and antidiabetic medications might improve arterial stiffness in OSA patients $[31,32]$. Thus, it is plausible that the presence of these comorbidities and the use of medication may negate a possible relationship between OSA and arterial stiffness in the elderly via the mixture of a ceiling effect of increased stiffness and a medication effect of decreasing arterial stiffness. Although we found a modest but significant association between AHI and arterial stiffness after eliminating the potential confounding effects of medical conditions and medication use, we should be cautious about the interpretation of these results. The healthy OSA subgroup consisted of only a quarter of all the subjects, so whether they were representative is debatable. Still, we believe that our analyses are of value because we removed the confounding effects of comorbidities/medications in order to explore the isolated impact of OSA on cardiovascular risk in the elderly.

CRP is an important serum biomarker of inflammation that can predict cardiovascular risk in apparently healthy subjects [33] and in heart-failure patients with central sleep apnea [34]. However, the association between CRP and OSA is controversial [15, 35-37]. Previously, we showed that CRP was associated with obesity rather than with AHI [25]. It should be noted that the subjects of the previous study were middle-aged men $(42.1 \pm 8.7$ years, $n=90)$ and not from the elderly population. In this context, the study of Roche et al. [15] in 2009 is relevant to this study because their subjects included the elderly who had OSA without cardiovascular morbidity. Their study population was similar to ours, especially 
the healthy group, and they also showed a significant association between CRP and OSA. Therefore, the discovery of the association between CRP and OSA might indicate a characteristic of the elderly population without comorbidities.

The issue of potential ceiling effects deserves further comment. The patients with OSA and comorbidities did not have worse vascular stiffness than those with comorbidities only, so the possibility exists that a 'maximum' stiffness in elderly humans occurs, above which further worsening is unlikely. Both biological as well as methodological explanations could play a role here. For example, OSA and diabetes mellitus could work through autonomic, inflammatory or oxidative stress mechanisms such that the combination of diseases may not worsen risk, at least as assessed through vascular stiffness [38, 39]. The instrumentation required to measure PWV may also have reduced sensitivity at maximal values such that measurement of increased vascular stiffness may be problematic in some patients. As our patients with severe OSA and comorbidities did not have velocities greater than the other groups, we suggest that our findings are more likely to be driven by biological rather than methodological issues. However, further work is clearly needed in this area.

The main strengths of this study was the large number of subjects with laboratory polysomnographic data and the detailed medical evaluation, which enabled us to stratify the subjects based on the presence or absence of medical illness. However, we also acknowledge some limitations. First, the elderly without comorbidities com- prised only a quarter of our subjects, which limited the statistical power. We could therefore parsimoniously suggest that comorbidities and their medications attenuate the impact of OSA on arterial stiffness. Second, we found modest correlations between AHI and cardiovascular variables, indicating that other factors might also influence these variables. Third, arterial stiffness is an early marker of atherosclerosis. This is a good cardiovascular marker for the middle-aged population, but may not be ideal for the elderly, because the ceiling effect of arterial stiffness might be present in this group, especially in the patients with comorbidities. Despite these limitations, we could conclude that OSA was associated with increased arterial stiffness in an otherwise healthy, elderly population. This association was obviated by comorbidities and medications perhaps due to ceiling effects.

\section{Acknowledgement}

This study was supported by the Basic Science Research Program through the National Research Foundation of Korea funded by the Ministry of Education, Science and Technology (I.Y.Y.), grant No. 2010-0008886. Dr. Malhotra is supported by the National Institutes of Health.

\section{Financial Disclosure and Conflicts of Interest}

The authors have no conflicts of interest. Dr. Malhotra relinquished all outside personal sources of income in 2012.

\section{References}

1 Ancoli-Israel S, Kripke DF, Klauber MR, Fell R, Stepnowsky C, Estline E, Khazeni N, Chinn A: Morbidity, mortality and sleep-disordered breathing in community dwelling elderly. Sleep 1996;19:277-282.

-2 Lee SD, Kang SH, Ju G, Han JW, Kim TH, Lee CS, Kim T, Kim KW, Yoon IY: The prevalence of and risk factors for sleep-disordered breathing in an elderly Korean population. Respiration 2014;87:372-378.

3 Peppard PE, Young T, Barnet JH, Palta M, Hagen EW, Hla KM: Increased prevalence of sleep-disordered breathing in adults. Am J Epidemiol 2013;177:1006-1014.

-4 Gottlieb DJ, Yenokyan G, Newman AB, O'Connor GT, Punjabi NM, Quan SF, Redline S, Resnick HE, Tong EK, Diener-West M, Shahar E: Prospective study of obstructive sleep apnea and incident coronary heart disease and heart failure: the Sleep Heart Health Study. Circulation 2010;122:352-360.
5 Redline S, Yenokyan G, Gottlieb DJ, Shahar E, O'Connor GT, Resnick HE, Diener-West M, Sanders MH, Wolf PA, Geraghty EM, Ali T, Lebowitz M, Punjabi NM: Obstructive sleep apnea-hypopnea and incident stroke: the Sleep Heart Health Study. Am J Respir Crit Care Med 2010;182:269-277.

-6 Young T, Finn L, Peppard PE, Szklo-Coxe M, Austin D, Nieto FJ, Stubbs R, Hla KM: Sleep disordered breathing and mortality: eighteenyear follow-up of the Wisconsin sleep cohort. Sleep 2008;31:1071-1078.

7 Barcelo A, Esquinas C, Pierola J, De la Pena M, Sanchez-de-la-Torre M, Montserrat JM, Marin JM, Duran J, Arque M, Bauca JM, Barbe F: Vitamin D status and parathyroid hormone levels in patients with obstructive sleep apnea. Respiration 2013;86:295301.

8 Endeshaw YW, White WB, Kutner M, Ouslander JG, Bliwise DL: Sleep-disordered breathing and 24-hour blood pressure pattern among older adults. J Gerontol A Biol Sci Med Sci 2009;64:280-285.

-9 Martinez-Garcia MA, Campos-Rodriguez F, Catalan-Serra P, Soler-Cataluna JJ, AlmeidaGonzalez C, De la Cruz Moron I, Duran-Cantolla J, Montserrat JM: Cardiovascular mortality in obstructive sleep apnea in the elderly: role of long-term continuous positive airway pressure treatment. A prospective observational study. Am J Respir Crit Care Med 2012; 186:909-916.

10 Haas DC, Foster GL, Nieto FJ, Redline S, Resnick HE, Robbins JA, Young T, Pickering TG: Age-dependent associations between sleep-disordered breathing and hypertension: importance of discriminating between systolic/diastolic hypertension and isolated systolic hypertension in the Sleep Heart Health Study. Circulation 2005;111:614621. 
11 Punjabi NM, Caffo BS, Goodwin JL, Gottlieb DJ, Newman AB, O'Connor GT, Rapoport DM, Redline S, Resnick HE, Robbins JA, Shahar E, Unruh ML, Samet JM: Sleep-disordered breathing and mortality: a prospective cohort study. PLoS Med 2009;6:e1000132.

-12 Phillips CL, Butlin M, Wong KK, Avolio AP: Is obstructive sleep apnoea causally related to arterial stiffness? A critical review of the experimental evidence. Sleep Med Rev 2013;17: 7-18.

13 Kumagai T, Kasai T, Kato M, Naito R, Maeno K, Kasagi S, Kawana F, Ishiwata S, Narui K: Establishment of the cardio-ankle vascular index in patients with obstructive sleep apnea. Chest 2009;136:779-786.

14 Chung S, Yoon IY, Lee CH, Kim JW: The association of nocturnal hypoxemia with arterial stiffness and endothelial dysfunction in male patients with obstructive sleep apnea syndrome. Respiration 2010;79:363-369.

-15 Roche F, Gaspoz JM, Pichot V, Picard-Kossovsky M, Maudoux D, Garcin A, Celle S, Sforza E, Barthelemy JC; Proof and SYNAPSE Study Groups: Association between C-reactive protein and unrecognised sleep-disordered breathing in the elderly. Eur Respir J 2009;33:797-803.

-16 Trzepizur W, Le Vaillant M, Meslier N, Pigeanne T, Masson P, Humeau MP, BizieuxThaminy A, Goupil F, Chollet S, Ducluzeau PH, Gagnadoux F; Institut de Recherche en Santé Respiratoire des Pays de la Loire Sleep Cohort Group: Independent association between nocturnal intermittent hypoxemia and metabolic dyslipidemia. Chest 2013;143: 1584-1589.

17 Rechtschaffen A, Kales A (eds): A Manual of Standardized Terminology, Technique, and Scoring System for Sleep Stages of Human Subjects. Los Angeles, UCLA Brain Information Service/Brain Research Institute, 1968.

18 American Academy of Sleep Medicine Task Force: Sleep-related breathing disorders in adults: recommendations for syndrome definition and measurement techniques in clinical research. Report of an American Academy of Sleep Medicine Task Force. Sleep 1999;22: 667-689.

19 Yu WC, Chuang SY, Lin YP, Chen CH: Brachial-ankle vs. carotid-femoral pulse wave velocity as a determinant of cardiovascular structure and function. J Hum Hypertens 2008;22:24-31.
20 Yamashina A, Tomiyama H, Takeda K, Tsuda H, Arai T, Hirose K, Koji Y, Hori S, Yamamoto Y: Validity, reproducibility, and clinical significance of noninvasive brachial-ankle pulse wave velocity measurement. Hypertens Res 2002;25:359-364.

21 Vlachopoulos C, Aznaouridis K, Stefanadis C: Prediction of cardiovascular events and allcause mortality with arterial stiffness: a systematic review and meta-analysis. J Am Coll Cardiol 2010;55:1318-1327.

22 Garcia-Rio F, Pino JM, Alonso A, Arias MA, Martinez I, Alvaro D, Villamor J: White coat hypertension in patients with obstructive sleep apnea-hypopnea syndrome. Chest 2004; 125:817-822.

23 Shirai K, Utino J, Otsuka K, Takata M: A novel blood pressure-independent arterial wall stiffness parameter; cardio-ankle vascular index (CAVI). J Atheroscler Thromb 2006;13: 101-107.

24 Agabiti-Rosei E, Mancia G, O’Rourke MF, Roman MJ, Safar ME, Smulyan H, Wang JG, Wilkinson IB, Williams B, Vlachopoulos C: Central blood pressure measurements and antihypertensive therapy: a consensus document. Hypertension 2007;50:154-160.

25 Chung S, Yoon IY, Shin YK, Lee CH, Kim JW, Lee T, Choi DJ, Ahn HJ: Endothelial dysfunction and C-reactive protein in relation with the severity of obstructive sleep apnea syndrome. Sleep 2007;30:997-1001.

26 Ayers L, Stoewhas AC, Ferry B, Stradling J, Kohler M: Elevated levels of endothelial cellderived microparticles following short-term withdrawal of continuous positive airway pressure in patients with obstructive sleep apnea: data from a randomized controlled trial. Respiration 2013;85:478-485.

27 Koivistoinen T, Virtanen M, Hutri-Kahonen N, Lehtimaki T, Jula A, Juonala M, Moilanen L, Aatola H, Hyttinen J, Viikari JS, Raitakari OT, Kahonen M: Arterial pulse wave velocity in relation to carotid intima-media thickness, brachial flow-mediated dilation and carotid artery distensibility: the Cardiovascular Risk in Young Finns Study and the Health 2000 Survey. Atherosclerosis 2012;220:387-393.

28 Buchner NJ, Quack I, Woznowski M, Stahle C, Wenzel U, Rump LC: Microvascular endothelial dysfunction in obstructive sleep apnea is caused by oxidative stress and improved by continuous positive airway pressure therapy. Respiration 2011;82:409-417.
29 Urbina EM, Kimball TR, Khoury PR, Daniels SR, Dolan LM: Increased arterial stiffness is found in adolescents with obesity or obesityrelated type 2 diabetes mellitus. J Hypertens 2010;28:1692-1698.

-30 Safar ME, Balkau B, Lange C, Protogerou AD, Czernichow S, Blacher J, Levy BI, Smulyan H: Hypertension and vascular dynamics in men and women with metabolic syndrome. J Am Coll Cardiol 2013;61:12-19.

31 Takami T, Saito Y: Azelnidipine plus olmesartan versus amlodipine plus olmesartan on arterial stiffness and cardiac function in hypertensive patients: a randomized trial. Drug Des Devel Ther 2013;7:175-183.

- 32 Boutouyrie P, Lacolley P, Briet M, Regnault V, Stanton A, Laurent S, Mahmud A: Pharmacological modulation of arterial stiffness. Drugs 2011;71:1689-1701.

-33 Ridker PM: High-sensitivity C-reactive protein: potential adjunct for global risk assessment in the primary prevention of cardiovascular disease. Circulation 2001;103:1813-1818.

- 34 Schmalgemeier H, Bitter T, Fischbach $\mathrm{T}$, Horstkotte $\mathrm{D}$, Oldenburg O: C-reactive protein is elevated in heart failure patients with central sleep apnea and Cheyne-Stokes respiration. Respiration 2014;87:113-120.

35 Shamsuzzaman AS, Winnicki M, Lanfranchi P, Wolk R, Kara T, Accurso V, Somers VK: Elevated C-reactive protein in patients with obstructive sleep apnea. Circulation 2002; 105:2462-2464.

36 Guven SF, Turkkani MH, Ciftci B, Ciftci TU, Erdogan Y: The relationship between highsensitivity C-reactive protein levels and the severity of obstructive sleep apnea. Sleep Breath 2012;16:217-221.

- 37 Chirinos JA, Gurubhagavatula I, Teff K, Rader DJ, Wadden TA, Townsend R, Foster GD, Maislin G, Saif H, Broderick P, Chittams J, Hanlon AL, Pack AI: CPAP, weight loss, or both for obstructive sleep apnea. N Engl J Med 2014;370:2265-2275.

38 Doupis J, Rahangdale S, Gnardellis C, Pena SE, Malhotra A, Veves A: Effects of diabetes and obesity on vascular reactivity, inflammatory cytokines, and growth factors. Obesity (Silver Spring) 2011;19:729-735.

39 Yim-Yeh S, Rahangdale S, Nguyen AT, Jordan AS, Novack V, Veves A, Malhotra A: Obstructive sleep apnea and aging effects on macrovascular and microcirculatory function. Sleep 2010;33:1177-1183. 